\title{
The National Collaborating Centre for Healthy Public Policy in times of COVID-19: Building skills to "Build Back Better"
}

\author{
Olivier Bellefleur ${ }^{1 *}$, Marianne Jacques ${ }^{1}$
}

\begin{abstract}
This article, the second in a series on the six National Collaborating Centres for Public Health, focuses on the National Collaborating Centre for Healthy Public Policy (NCCHPP), a centre of expertise, and knowledge synthesis and sharing that supports public health actors in Canada in their efforts to develop and promote healthy public policy.

The article briefly describes the NCCHPP's mandate and programming, noting some of the resources that are particularly relevant in the current coronavirus disease 2019 (COVID-19) context. It then discusses how the NCCHPP's programming has been adapted to meet the changing needs of public health actors throughout the pandemic. These needs have been strongly tied to decisions aimed at containing the spread of the severe acute respiratory syndrome coronavirus 2 (SARS-CoV-2) and mitigating its immediate impacts in various societal sectors since the beginning of the crisis. Needs have also gradually emerged related to how public health is expected to help inform the development of public policies that will allow us to "build back better" societies as we recover from the pandemic. The article concludes by discussing the orientation of the NCCHPP's future work as we emerge from the COVID-19 crisis.
\end{abstract}

This work is licensed under a Creative Commons Attribution 4.0 International License.

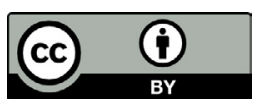

Affiliation

${ }^{1}$ National Collaborating Centre for Healthy Public Policy, Institut national de santé publique du Québec, Montréal, OC

\section{*Correspondence:}

olivier.bellefleur@inspq.qc.ca

Suggested citation: Bellefleur O, Jacques M. The National Collaborating Centre for Healthy Public Policy in times of COVID-19: Building skills to "Build Back Better". Can Commun Dis Rep 2021;47(4):232-6.

https://doi.org/10.14745/ccdr.v47i04a08

Keywords: COVID-19, SARS-CoV-2, healthy public policy, knowledge translation, recovery

\section{Introduction}

The National Collaborating Centre for Healthy Public Policy (NCCHPP) is part of a network of six National Collaborating Centres for Public Health (NCCs) established in 2005 by the federal government as part of an effort to renew and strengthen Canada's public health infrastructure in the wake of the epidemic caused by the severe acute respiratory syndrome coronavirus (SARS-CoV-1) (1). The NCCs are funded by the Public Health Agency of Canada (PHAC) and their goal is to support the timely use of scientific and other knowledge-based evidence to inform public health practice, programs and policy in Canada. More specifically, the NCCs' mandate is to develop, synthesize and share knowledge, identify research gaps and the knowledge needs of public health actors, and foster the development of networks among public health professionals, researchers and policy makers across Canada. Each of the NCCs specializes in a specific area of public health and is hosted by a Canadian university or governmental organization (2).
This article is the second in a series of articles describing each of the NCCs and their contribution to the response to the coronavirus disease 2019 (COVID-19). It focuses on the NCCHPP, a centre specializing in healthy public policy hosted by the Institut national de santé publique du Québec (INSPQ) in Montréal. The article begins with a brief presentation of the NCCHPP's mandate and programming, describing some of the resources that are particularly relevant to the current COVID-19 context, and then focuses on adjustments that have been made to maintain the Centre's relevance in the context of the pandemic.

\section{A Centre devoted to healthy public policy}

The NCCHPP is a centre of expertise whose mandate is to support public health actors in Canada in their efforts to develop and promote healthy public policy. These policies shape the 
"circumstances in which people are born, grow up, live, work and age" (3). In other words, they are levers for acting on the social, cultural, ecological and economic determinants of health (4). Thus, even when these policies fall under the responsibility of non-health government sectors, they have the potential to significantly impact population health and health inequalities $(5,6)$. Such policies may include, for example, housing, education, transport, environmental and income policies. It is therefore not surprising that building healthy public policy was identified as one of the pillars of health promotion by the World Health Organization (WHO) in the Ottawa Charter (7).

\section{An updated program}

In 2019, PHAC renewed funding for the NCCs for an eight-year period, reaffirming the added value the NCCs bring to Canada's public health infrastructure. The NCCHPP's new programming is organized around three axes, whose overarching goal is to support the development of the individual skills and organizational capacity required to act to promote healthy public policy.

The first axis of the NCCHPP's programming is devoted to the development of resources and knowledge-sharing activities aimed at facilitating policy analysis, improving understanding of public policy processes, and assisting actors in more effectively sharing knowledge within these processes. These resources and activities seek to strengthen public policy competencies, which are recognized as essential within public health $(8,9)$; given that policies are indispensable levers for acting upstream and in a structuring manner to benefit population health and reduce health inequalities. The NCCHPP's resources include two online courses, one on a framework for analyzing public policies (10) and the other on public health ethics (11). These courses have been taken by nearly 3,000 and 2,000 participants respectively since their launch and are included in the curricula of several Canadian universities. The NCCHPP's resources related to this axis also include various documents focused, in particular, on working with municipalities (12), policy approaches to reducing health inequalities (13), policy agenda setting (14), and public policy competencies for public health (8).

As part of the second axis of its programming, the NCCHPP develops and shares resources related to intersectoral approaches to integrating a public health perspective into the policies, programs and projects of other government sectors such that they address health determinants and health inequalities. The NCCHPP focuses mainly on two approaches promoted by the WHO: Health in All Policies (HiAP) and Health Impact Assessment (HIA) $(15,16)$. These two approaches have been put forward in recent years as a way to act upstream on health, wellbeing and health equity in Canada (17-19) and calls to take action to further their implementation have multiplied since the beginning of the pandemic $(20,21)$. To support their implementation, the NCCHPP has developed, among other things, an online training course on HIA (22), which has been taken by nearly 3,000 participants since its launch, as well as various documents on HIA and HiAP (23-26). The NCCHPP's expertise in the area of HiAP has also enabled it to assume the mandate of secretariat for the Global Network for Health in All Policies, a network affiliated with the WHO. It allows the Centre to remain in close contact with international actors in the field of HiAP and to facilitate networking and knowledge sharing with Canadian actors.

Finally, the NCCHPP uses the approaches, methods and tools developed in its first two program axes to address emerging or priority public health issues in the third axis of its programming. This axis of the NCCHPP's program involves working on population mental health and wellness, climate issues and, for the past year or so, COVID-19. For several years, the NCCHPP has been working with its partners to clarify the roles of public health actors in promoting population mental health and wellness, to identify the needs associated with these roles, and to respond to these needs. Activities have included hosting a pan-Canadian forum (27), developing an inventory of mental health strategies in Canada (28), and producing a framework for supporting action in population mental health (29) that has been used in several jurisdictions, including Ontario, to support the implementation of the Mental Health Promotion Public Health Standards. More recently, the NCCHPP has also begun work on policy approaches to reducing the health risks associated with climate change, in particular by exploring the potential of the ecological economics model (30) and by identifying tools and methods for integrating health into climate change adaptation or mitigation policies and strategies (31).

\section{The National Collaborating Centre for Healthy Public Policy in times of COVID-19}

Since the beginning of the pandemic, public health actors have been heavily involved in government-wide efforts to contain the spread of the SARS-CoV-2 virus and to mitigate its immediate impacts on different sectors of society. As the pandemic has evolved, efforts to mitigate its medium and long-term effects on population health and wellbeing have expanded. Some public health actors are also being called upon to contribute to efforts to "build back better" societies, notably through action on healthy public policy (20). Anticipating this development, the NCCHPP quickly adapted its programming to meet certain pressing needs, but above all to prepare appropriate resources to help mitigate the medium and long-term effects of the pandemic and to "build back better" societies.

As early as March 2020, the NCCHPP developed and made available online a directory of selected resources to facilitate the integration of an ethical dimension in decisions related to COVID-19 (32). The directory, which is updated regularly, 
provides a brief summary of each resource and groups them into categories (frameworks, equity, Indigenous health, communication, etc.) for easy retrieval. It has been referenced by multiple actors, including the Québec Population Health Research Network, the First Nations Health Consortium in Alberta, and Manitoba Shared Care.

The NCCHPP has also coordinated the development of an initiative involving all six NCCs, in partnership with the Canadian Institutes of Health Research (CIHR). Through this initiative, the NCCs are leveraging their knowledge translation expertise, their networks and their dissemination channels to support efforts to mobilize and disseminate new knowledge arising from CIHR-funded research projects related to COVID-19. To date, this initiative has provided support to 23 research teams across Canada.

Responding to the earliest calls for action to "build back better" societies, the NCCHPP began a series of documents on "wellbeing budgets," which could offer a promising pathway for governments intent on achieving an economic recovery focused on improving the wellbeing of citizens. This is an approach to integrating wellbeing indicators into government budgeting processes. While interest in this approach existed in Canada prior to the pandemic (as evidenced, for example, by the federal Minister of Middle Class Prosperity and Associate Minister of Finance mandate letter (33)), this interest has only deepened during the pandemic $(34,35)$.

Finally, the NCCHPP, together with the Global Network for Health in All Policies and WHO, has undertaken to document the potential of the HiAP approach to contribute to gradually transform the intersectoral collaboration observed since the beginning of the pandemic. One of the anticipated challenges will be to redirect this collaboration toward longer-term objectives related to the promotion of health, wellbeing and equity $(20,21)$. To this end, the NCCHPP worked with its Canadian and international partners to deliver a series of webinars focused on the HiAP approach in times of COVID-19 (36). These activities attracted just over 300 participants and garnered very positive evaluations, particularly as a means of knowledge acquisition and for their relevance to public health practice. In the same vein, the NCCHPP has also begun work on establishing a Canadian network for HiAP in partnership with the PHAC.

\section{Conclusion}

The NCCHPP is a centre of expertise that works to build public health skills and capacity for intersectoral action on healthy public policy by offering a range of resources and activities. With the advent of COVID-19, the NCCHPP quickly adapted its programming not only to meet some of the pressing needs of public health actors, but above all to develop resources to support longer-term public health action on the determinants of health affected by the pandemic and on the widening of health inequalities in Canada.

Future work will build on the initiatives outlined in this article. However, given the likelihood of forthcoming pressures to balance budgets at all levels of government, work will also be done to examine the opportunities and challenges that these pressures present for intersectoral collaboration that benefits health and health equity. In short, the NCCHPP will continue to work with all of its partners to support public health actors who wish to act on public policy to mitigate the medium and long-term impacts of the pandemic, to "build back better" societies, and to strengthen our resilience in the face of future crises.

\section{Authors' statement}

$\mathrm{OB}-$ Conceptualization, drafting of original text, review and revision

MJ - Conceptualization, substantive commenting, revision

\section{Competing interests}

None.

\section{Funding}

The authors are employed by the Institut national de santé publique du Québec to work at the National Collaborating Centre for Healthy Public Policy, which is funded by the Public Health Agency of Canada.

\section{References}

1. Medlar B, Mowat D, Di Ruggiero E, Frank J. Introducing the National Collaborating Centres for Public Health. CMAJ 2006;175(5):493-4. DOI PubMed

2. Dubois A, Lévesque M. Canada's National Collaborating Centres: facilitating evidence-informed decision-making in public health. Can Commun Dis Rep 2020;46(2-3):31-5. DOl PubMed

3. World Health Organization. (2020). Social determinants of health. https://www.who.int/health-topics/social-determinant s-of-health\#tab=tab_1

4. Parkes MW, Poland B, Allison S, Cole DC, Culbert I, Gislason MK, Hancock T, Howard C, Papadopoulos A, Waheed F. Preparing for the future of public health: ecological determinants of health and the call for an eco-social approach to public health education. Can J Public Health 2020;111(1):60-4. DOI PubMed 
5. Hancock T. Beyond health care: from public health policy to healthy public policy. Can J Public Health 1985;76 Suppl 1:9-11. PubMed

6. Harris P, Wise M. (2020). Healthy Public Policy. Oxford Bibliographies. https://www.oxfordbibliographies.com/view/ document/obo-9780199756797/obo-9780199756797-0196. $\mathrm{xml}$

7. World Health Organization. (1986). Ottawa Charter. http://www.euro.who.int/_data/assets/pdf_ file/0004/129532/Ottawa_Charter.pdf

8. Ngne AK, Morrison V. (2021). Public policy competencies for public health: A review of the literature. National Collaborating Centre for Healthy Public Policy. http://www. ncchpp.ca/172/publications.ccnpps?id_article=2099

9. Benoit F, Martin C, Malai D. (2015). A public policy competency framework for public health actors. National Collaborating Centre for Healthy Public Policy. http://www. ncchpp.ca/165/publications.ccnpps?id_article=1513

10. National Collaborating Centre for Healthy Public Policy. (2017). Online course - A framework for analyzing public policies. http://www.ncchpp.ca/438/online-course.ccnpps

11. National Collaborating Centre for Healthy Public Policy. (2020). Online course: An introduction to public health ethics. http://www.ncchpp.ca/872/online-course.ccnpps

12. Morestin F. (2020). How to collaborate with municipalities? A practical guide for public health actors. National Collaborating Centre for Healthy Public Policy. http://www. ncchpp.ca/181/publications.ccnpps?id_article $=2078$

13. Mantoura P, Morrison V. (2016). Policy approaches to reducing health inequalities. National Collaborating Centre for Healthy Public Policy. http://www.ncchpp.ca/141/ publications.ccnpps?id_article $=1548$

14. Bendaoud M. (2020). Understanding public policy agenda setting using the 4 p's model: Power, perception, potency and proximity. National Collaborating Centre for Healthy Public Policy. http://www.ncchpp.ca/165/publications. ccnpps?id_article $=2085$

15. World Health Organization. (2013). The Helsinki statement on health in all policies. https://www.who.int/ healthpromotion/conferences/8gchp/statement_2013/en/

16. World Health Organization Regional Office for Europe. (1999). Health Impact Assessment: Main concepts and suggested approach. (Gothenburg consensus paper). http://www.healthedpartners.org/ceu/hia/hia01/01_02_ gothenburg_paper_on_hia_1999.pdf

17. Diallo T. (2019). Preparatory reading. Pan-Canadian meeting on Health in All Policies (HiAP) Québec, October 9, 2019. National Collaborating Centre for Healthy Public Policy. http://www.ncchpp.ca/docs/2019-GouvlntGov-GNHiA P-RencontreMeeting-Preparatory-Reading.pdf
18. Diallo T. (2020). Report of the Pan-Canadian meeting on Health in All Policies (HiAP). Québec, October 9, 2019. National Collaborating Centre for Healthy Public Policy. http://www.ncchpp.ca/148/publications.ccnpps?id_ article $=2072$

19. Tonelli M, Tang KC, Forest PG. Canada needs a "Health in All Policies" action plan now. CMAJ 2020;192(3):E61-7. DOI PubMed

20. Public Health Agency of Canada. (2020). Chief Public Health Officer of Canada's Report on the State of Public Health in Canada 2020. From risk to resilience: An equity approach to COVID-19. https://www.canada. ca/en/public-health/corporate/publications/chief-publi c-health-officer-reports-state-public-health-canada/from-ris k-resilience-equity-approach-covid-19.html

21. Ruggiero ED, Papadopoulos A, Steinberg $M$, Blais $R$, Frandsen N, Valcour J, Penney G. (2020). Strengthening collaborations at the public health system-academic interface: a call to action. Canadian Journal of Public Health. https://link.springer.com/article/10.17269/s41997-02000436-w

22. National Collaborating Centre for Healthy Public Policy. (2020). Online course - Health Impact Assessment, step by step. http://www.ncchpp.ca/274/online-course.ccnpps

23. National Collaborating Centre for Healthy Public Policy. (2014). Health Impact Assessment (HIA) toolbox - Cost calculator, screening grid, and scoping tool. http://www. ncchpp.ca/133/publications.ccnpps?id_article=1215

24. National Collaborating Centre for Healthy Public Policy. (2019). Preparing and conducting work meetings within the context of the health impact assessment process. http:// www.ncchpp.ca/133/publications.ccnpps?id_article=2024

25. St-Pierre L. (2017). Selected tools to facilitate the integration of Health in All Policies. National Collaborating Centre for Healthy Public Policy. http://www.ncchpp.ca/148/ publications.ccnpps?id_article $=1642$

26. Diallo T. (2020). Five examples of intersectoral action for health at the local and regional level in Canada. National Collaborating Centre for Healthy Public Policy. http://www. ncchpp.ca/148/publications.ccnpps?id_article=2036

27. National Collaborating Centres for Public Health. (n.d.) Population mental health. https://nccph.ca/projects/ mentalhealth/

28. Arulthas S. (2018). Scan of mental health strategies in Canada. National Collaborating Centre for Healthy Public Policy. http://www.ncchpp.ca/553/publications.ccnpps?id_ article=1905

29. Mantoura P, Roberge MC, Fournier L. [A framework to support action in population mental health]. Sante Ment Que 2017;42(1):105-23. DOI PubMed 
30. Hancock T. (2020). Ecological economics and public health: An interview with Dr. Trevor Hancock. National Collaborating Centre for Healthy Public Policy. http://www.ncchpp.ca/867/ publications.ccnpps?id_article=2052

31. Diallo T. (2021). Tools and methods for integrating health into climate change adaptation and mitigation policies and strategies. National Collaborating Centre for Healthy Public Policy. http://www.ncchpp.ca/867/publications.ccnpps?id_ article $=2088$

32. National Collaborating Centre for Healthy Public Policy. (2020). Public health ethics and COVID-19: Selected resources. http://www.ncchpp.ca/823/covid19-selected-resources.ccnpps

33. Trudeau J. (2019). Minister of Middle Class Prosperity and Associate Minister of Finance Mandate Letter. Office of the Prime Minister. https://pm.gc.ca/en/ mandate-letters/2019/12/13/minister-middle-class-prosperit $y$-and-associate-minister-finance-mandate
34. Fleischer L. (2020). Three ways a well-being lens can aid COVID-19 recovery. The OECD Statistics Newsletter, (72), 3-6. https://www.oecd.org/sdd/ theoecdstatisticsnewsletter-allissues.htm

35. National Collaborating Centre for Healthy Public Policy. (2020). Wellbeing Budgeting and Public Health: Promising Practice for Pandemic Recovery? [video]. YouTube. https:// www.ncchpp.ca/554/presentations.ccnpps?id_article $=2083$

36. National Collaborating Centre for Healthy Public Policy. (2020). Health in All Policies in times of COVID-19: What roles for the health sector moving forward? [video]. YouTube. https://www.youtube.com/watch?v=C2wYERfAow0

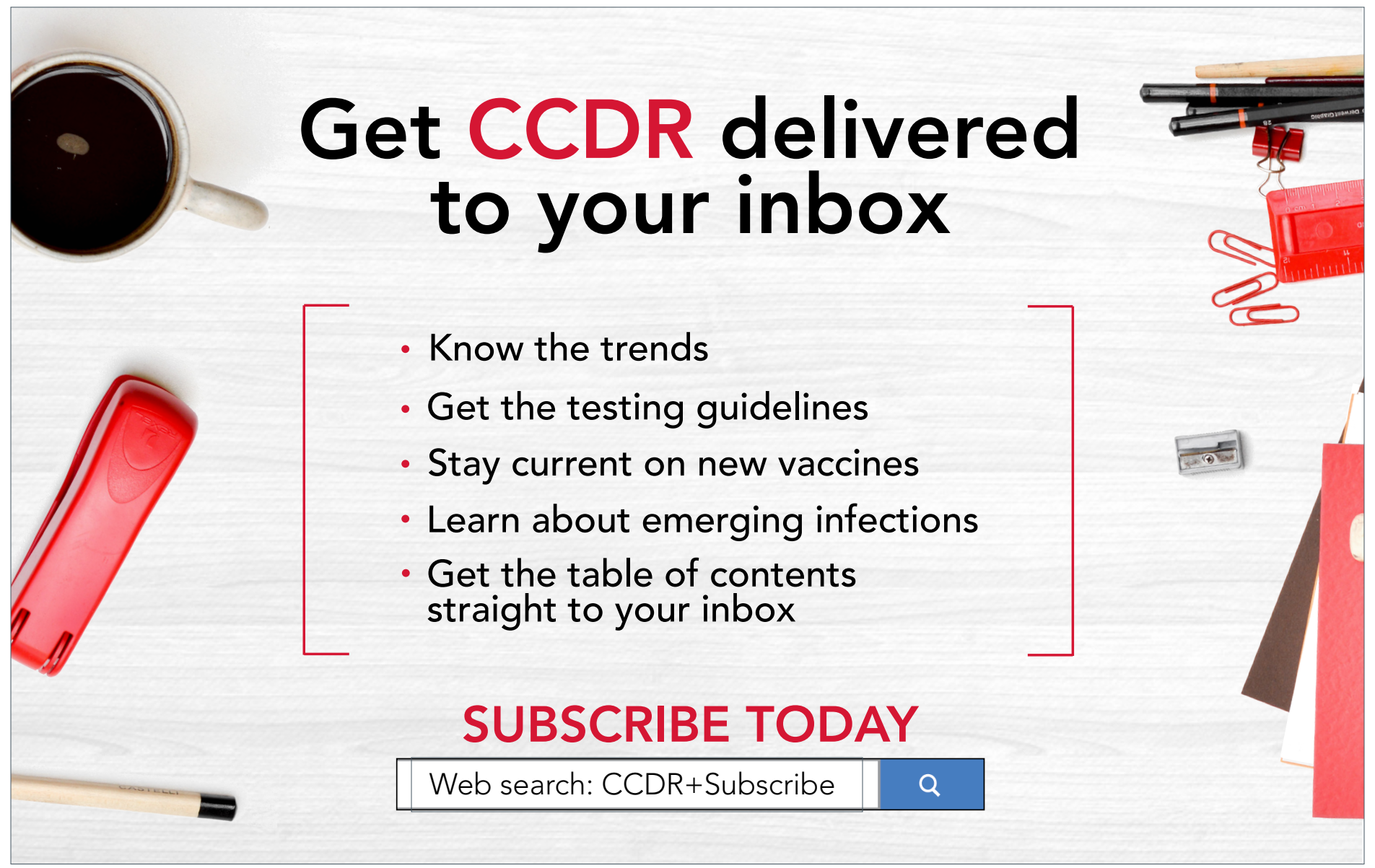

